\title{
Bacterial Lipopolysaccharides Prime Human Neutrophils for Enhanced Production of Leukotriene $\mathrm{B}_{\mathbf{4}}$
}

Martin E. Doerfler, Robert L. Danner, James H. Shelhamer, and Joseph E. Parrillo

Critical Care Medicine Department, Clinical Center, National Institutes of Health, Bethesda, Maryland 20892

\begin{abstract}
Neutrophils can be "primed" for an enhanced respiratory burst by lipopolysaccharide (LPS) in concentrations measurable in patients with septic shock. Leukotriene $\mathrm{B}_{4}\left(\mathrm{LTB}_{4}\right)$ is the primary eicosanoid product of neutrophils and is felt to be a mediator of host defense and inflammation. We investigated the in vitro effects of LPS on neutrophil production of $\mathbf{L T B}_{4}$ and the omega-oxidation metabolites of $\mathrm{LTB}_{4}$. Incubation of neutrophils with LPS in concentrations ranging from 0.01 to 100 $\mathrm{ng} / \mathrm{ml}$ did not result in production of $\mathrm{LTB}_{4}$ or metabolites in the absence of a second stimulus. Priming neutrophils with LPS and then stimulating with opsonized zymosan, phorbolmyristate-acetate or a low concentration of the calcium ionophore A23187 resulted in enhanced production of LTB $_{4}$. LPS priming of neutrophils occurred in a concentration dependent manner. LPS did not result in $\mathrm{LTB}_{4}$ production in response to the chemoattractant peptide FMLP. LPS priming of neutrophils had no effect on cytosolic calcium concentrations of resting or zymosan-stimulated cells. These results suggest that LPS might effect host defense and tissue injury by potentiating the effect of other stimulants on neutrophil production of LTB $_{4}$. This LPS induced enhancement may represent an important pathogenetic pathway in patients with gram negative sepsis.
\end{abstract}

\section{Introduction}

The polymorphonuclear leukocyte is a major target for the action of bacterial endotoxin (lipopolysaccharide, LPS). LPS in concentrations as low as $1.0 \mathrm{ng} / \mathrm{ml}$ has been shown to "prime" human neutrophils for an enhanced respiratory burst in response to the chemoattractant peptide FMLP, or opsonized zymosan $\left(\mathrm{OZ} ;{ }^{1} 1\right)$. This concentration of endotoxin is similar to that found in patients with septic shock (2). More recently it has been shown that endotoxin in similar concentrations can prime the mouse peritoneal macrophage for enhanced release of eicosanoids, an event felt to be of significance in the response to bacterial infection (3).

The primary product of arachidonic acid metabolism in human neutrophils is leukotriene $\mathrm{B}_{4}\left(\mathrm{LTB}_{4}\right)$ or $5(s)$, 12(r)-di-

Address reprint requests to Dr. Doerfler, Critical Care Medicine Department, National Institutes of Health, Building 10, Room 10-D-48, Bethesda, MD 20892.

Received for publication 16 February 1988 and in revised form 11 October 1988.

1. Abbreviations used in this paper: $\mathrm{LTB}_{4}$, leukotriene $\mathrm{B}_{4} ; \mathrm{OZ}$, opsonized zymosan.

The Journal of Clinical Investigation, Inc.

Volume 83, March 1989, 970-977 hydroxy-6,14-cis-8,10-trans-eicosatetraenoic acid (4, 5). LTB $_{4}$ produces increased chemotactic and chemokinetic migration of neutrophils $(6,7) . \mathrm{LTB}_{4}$ stimulates neutrophils to release lysosomal enzymes $(7,8)$ and to produce superoxide $(9)$. In addition, this leukotriene appears to have a potential role in the modulation of $T$ cell populations $(10,11)$, and promotes fluid extravasation into the interstitium by neutrophil-dependent increases in vascular permeability $(12,13)$. These findings suggested that LPS might enhance host defense mechanisms and promote tissue injury via an effect on the production or metabolism of $\mathrm{LTB}_{4}$ by the neutrophil.

In this report we demonstrate that incubation of human neutrophils with LPS in concentrations as low as $0.1 \mathrm{ng} / \mathrm{ml}$ results in an enhanced production of $\mathrm{LTB}_{4}$ upon exposure to a variety of biologic response modifiers.

\section{Methods}

Laboratory glassware and sonicator micro-tips to be used through the priming step were thoroughly cleaned and baked in dry heat for $4 \mathrm{~h}$ at $180^{\circ} \mathrm{C}$ to render them free of contaminating LPS (14). All reagents and buffers to be used were determined to be LPS free by a chromogenic Limulus lysate assay (Whittaker M.A. Bioproducts, Walkersville, MD) sensitive to $10 \mathrm{pg} / \mathrm{ml}$ of United States standard endotoxin.

Preparation of neutrophils. Neutrophils were isolated from the venous blood of normal volunteers using standard techniques as previously described (15). The blood was anticoagulated with $5 \mathrm{U} / \mathrm{ml}$ of sterile pyrogen-free, preservative free heparin (porcine intestine; Weddel Pharmaceuticals, Wrexham, UK). Pyrogen-free dextran (United States Biochemical Corporation, Cleveland, OH) of 200,000-300,000 mol wt was prepared as a $3.0 \%$ solution in HBSS (Gibco Laboratories, Grand Island, NY) without calcium or magnesium (-). This was added to the blood in a 1:2 ratio and the blood-dextran mixture was allowed to stand at a slight angle for $20 \mathrm{~min}$. The straw colored supernatant was collected and layered onto $1 / 2$ volume of Ficoll-Hypaque (lymphocyte separation media; Organon Teknika Corp., Durham, $\mathrm{NC}$ ). This was then centrifuged at $250 \mathrm{~g}$ (Damon Centrifuge, model CRU-5000) for $30 \mathrm{~min}$ at $18^{\circ} \mathrm{C}$. The upper layers were discarded and the cell pellet subjected to cold, sterile, pyrogen-free water $(4 \mathrm{ml})$ for 30 s to lyse residual red blood cells, followed by the addition of $3 \%$ saline $(2 \mathrm{ml})$. The cells were resuspended in HBSS (-) and centrifuged at 250 $g$ for $10 \mathrm{~min}$ at $18^{\circ} \mathrm{C}$ to remove red cell fragments. The cell pellet was resuspended in cold, sterile HBSS $(-)$ and the cell concentration adjusted to $1 \times 10^{7}$ cells $/ \mathrm{ml}$ by quantitation in a counter (Coulter Electronics, Inc., Hialeah, FL). Neutrophils obtained were $>98 \%$ pure by Wright's stain and $>98 \%$ viable by trypan blue exclusion.

Preparation of endotoxin. Highly purified protein-free LPS extracted from Salmonella Minnesota Re595 mutant (List Biological Laboratories, Campbell, CA) was prepared as a stock solution (1 $\mathrm{mg} / \mathrm{ml}$ ) in sterile, pyrogen-free water and sonicated for $4 \mathrm{~min}$ at maximum output (model 16-850; Virtis Co., Gardiner, NY), then stored at $-70^{\circ} \mathrm{C}$. On the day of use the LPS was thawed, sonicated for an additional $2 \mathrm{~min}$, and then adjusted to the desired final concentration in HBSS (-).

Neutrophil priming by LPS. Neutrophils suspended in HBSS (-) were mixed 1:1 with additional buffer with or without LPS to achieve a final concentration of $5 \times 10^{6} \mathrm{cells} / \mathrm{ml}$ and incubated in a shaking 
water bath according to the method of Guthrie et al. (1). In most experiments $1 \mathrm{ml}$ of the cell mixture was used. $4 \mathrm{ml}$ of the cell mixture was used to increase the sensitivity of the assay methods in one group of experiments using $\mathrm{OZ}$ as a stimulant for $\mathrm{LTB}_{4}$ production. An incubation time of $60 \mathrm{~min}$ was used in initial experiments based on the previously reported optimal incubation time for priming for enhanced superoxide generation $(1,15)$. Subsequently experiments were performed with the incubation times varied to determine the optimum duration of LPS exposure. After incubation, cells were examined microscopically to be certain that clumping had not occurred. Trypan blue exclusion always showed the neutrophils to be $>92 \%$ viable after incubation. Superoxide production was determined concurrently in some experiments to verify LPS priming of the respiratory burst as previously reported $(1,15)$. Superoxide was measured using a cytochrome $c$ assay as previously described (15).

Preparation of reagents. Ionophore A23187 (Ionophore; Calbiochem-Behring Corp., La Jolla, CA) was reconstituted from powder in ethanol and sonicated at maximal output for $2 \mathrm{~min}$ and then stored at $-20^{\circ} \mathrm{C}$. On the day of use the ionophore was again sonicated, diluted to final concentration in HBSS (-), and sonicated again.

Phorbol myristate acetate (PMA; Sigma Chemical Co., St. Louis, MO) was stored in initial stock solution $(1 \mathrm{mg} / \mathrm{ml})$ in dimethyl sulfoxide (DMSO; Sigma Chemical Co.) at $-20^{\circ} \mathrm{C}$. On the day of use the PMA stock solution was diluted to the desired concentration with HBSS (-).

$\mathrm{OZ}$ was prepared by first boiling zymosan (Sigma Chemical Co.) in $0.9 \% \mathrm{NaCl}$ to get a suspension free of clumping of the particles. This is cooled to room temperature and washed four times in sterile saline then incubated with fresh human serum at $37^{\circ} \mathrm{C}$ for $20 \mathrm{~min}$ (Lab-Line Instruments, Melrose Park, IL; 16). After centrifugation and four washings the $\mathrm{OZ}$ was suspended in $0.9 \% \mathrm{NaCl}$ at $50 \mathrm{mg} / \mathrm{ml}$.

FMLP (Sigma Chemical Co.) was stored at $-70^{\circ} \mathrm{C}$ in HBSS (-) and $10 \%$ DMSO at a final concentration of $0.1 \mathrm{mM}$. On the day of use the FMLP stock solution was diluted to the desired concentration with HBSS (-).

Fura $2 / \mathrm{AM}$ (Calbiochem) was stored at $-20^{\circ} \mathrm{C}$ in DMSO at a final concentration of $10 \mathrm{mM}$.

Stimulation of primed cells for $\mathrm{LTB}_{4}$ generation. After the incubation with LPS, calcium and magnesium salts were added to the cell suspension in the concentrations necessary to achieve a final solution equivalent to HBSS (+). Ionophore, OZ, PMA, or FMLP was then added, and the cell mixture was incubated for the desired time. The concentration of DMSO never exceeded $0.01 \%$, and the concentration of ethanol was never greater than $0.01 \%$ in the final solution. The mixture was vortexed frequently to maintain the cells in suspension. Incubations were terminated in most experiments with the addition of 1.5 volumes of iced ethanol (HPLC grade; Aldrich Chemical Co., Milwaukee, $\mathrm{WI}$ ) and the mixture refrigerated at $-20^{\circ} \mathrm{C}$ for at least $1 \mathrm{~h}$. Intracellular and extracellular $\mathrm{LTB}_{4}$ were determined in the experiments using $4 \mathrm{ml}$ of the neutrophil suspension and $\mathrm{OZ}$ as the second stimulant. The incubation was terminated by cooling at $4^{\circ} \mathrm{C}$ and centrifugation at $500 \mathrm{~g}$. The supernatant was decanted and the cell pellet resuspended in $100 \%$ methanol (HPLC grade; Burdick-Jackson Laboratories, Muskegon, MI) for $12 \mathrm{~h}$ at $4^{\circ} \mathrm{C}$ (17). Prostaglandin $\mathrm{B}_{2}(200$ $\mathrm{mg}$; Sigma Chemical Co.) was added as an internal standard to all experiments (18).

Extraction of eicosanoids. Polypropylene labware was used throughout the extraction process to avoid losses of the eicosanoids to glass surfaces. The cell mixture was centrifuged at $500 \mathrm{~g}$ (Accuspin; Beckman Instruments, San Ramon, CA) and the supernatant extracted on octadecyl-silane (ODS) C18 cartridges (Sep-pak; Waters Associates, Milford, MA; 18). Individual cartridges were prepared with $20 \mathrm{ml}$ of ethanol followed by $5 \mathrm{ml}$ of water (HPLC grade, Fisher Scientific, Pittsburgh, PA) Samples were diluted to $10 \%$ ethanol, and the $\mathrm{pH}$ adjusted to 3.2 with concentrated $\mathrm{HCl}$. Cartridges were eluted sequentially with $5.0 \mathrm{ml}$ of $10 \%$ (vol/vol) HPLC grade ethanol, $5 \mathrm{ml}$ of HPLC grade water, $10 \mathrm{ml}$ of petroleum ether (Fisher Scientific) and 4.0 $\mathrm{ml}$ of methyl-formate/(Eastman-Kodak Co., Rochester, NY; redis- tilled; 18) ethanol/acetic acid (90:10:0.02). The methyl-formate fraction is saved and evaporated to dryness under steady flow nitrogen gas (Evapo-rac; Cole-Parmer Medical Instruments, Chicago, IL) and resuspended in mobile phase (see below) for analysis by HPLC. The extraction efficiency for PGB2 was $94.0 \pm 3.0 \%(n=10)$, for $\mathrm{LTB}_{4}$ was $74.0 \pm 2.5 \%(n=10)$ and for radiolabeled $\mathrm{LTB}_{4}$ incubated with neutrophils (18) was $81.8 \pm 0.2 \%$. The recovery of $\mathrm{PGB}_{2}$ was used to correct for variances in recovery of $\mathrm{LTB}_{4}$ and the metabolites in individual experiments (18).

High performance liquid chromatography. A Beckman model 344 liquid chromatography system was used with dual pumps (model 114), an autosampler (model 506), and a variable wavelength ultraviolet detector (model 164) at $280 \mathrm{nM}$. An Ultrasphere C18 (Beckman) column $(4.7 \mathrm{~mm} \times 250 \mathrm{~mm}$ ) with $5-\mu \mathrm{m}$ particle size, was used along with an Ultrasphere $\mathrm{C} 18$ precartridge $(4.7 \mathrm{~mm} \times 45 \mathrm{~mm})$. The gradient program of Shak (18) was used with mobile phase A: methanol/acetonitrile/water/acetic acid (30:25:45:0.02), and mobile phase $B$ : methanol/acetonitrile (75:25). $\mathrm{LTB}_{4}$ standards, $\mathrm{PGB}_{2}$, and $\left[{ }^{3} \mathrm{H}\right] \mathrm{LTB}_{4}$ (Dupont, New England Nuclear, Boston, MA) were used as standards. $\mathrm{LTB}_{4}-\mathrm{COOH}$ and $\mathrm{LTB}_{4}-\mathrm{OH}$ were prepared from $\mathrm{LTB}_{4}$ and $\left[{ }^{3} \mathrm{H} \mathrm{LTB}_{4}\right.$ as described (18), and used for peak identification of $\mathrm{LTB}_{4}$ metabolites. Chromatogram plots and integrations for peak areas were accomplished using a Chromatopac C-R1B data processor (Shimadzu Corp., Kyoto, Japan). Concentrations of $\mathrm{LTB}_{4}$ and metabolites were obtained from the integrated areas by comparison to a standard curve with $R^{2}$ $=0.9977, n=5$, prepared under identical conditions. The accuracy of the standard curve was verified by comparison against a molar extinction coefficient in methanol at $281 \mathrm{~nm}$ of 39,500 as previously defined (19). The lower limits of detection of $\mathrm{LTB}_{4}$ was $1.0 \mathrm{ng}$. Using $5 \times 10^{6}$ cells/experiment, as little as $0.2 \mathrm{ng} / 10^{6}$ cells could be detected.

The presence of significant amounts of contaminating 5,12,DiHete or 5(s),12(s)-dihydroxy-6,14-cis-8,10-trans-eicosatetraenoic acid (20) was ruled out by chromatography of the methyl esters using the above system with an ultrasphere $\mathrm{Si}$ (Beckman) column $(4.7 \mathrm{~mm} \times 250 \mathrm{~mm})$ and precolumn $(4.7 \mathrm{~mm} \times 45 \mathrm{~mm})$ with $5-\mu \mathrm{m}$ bead size. Isocratic elution with hexane/2-propanol at $2.0 \mathrm{ml} / \mathrm{min}$ was performed as previously described $(18,21,22) .5,12$,DiHete never exceeded $3 \%$ of total $\mathrm{LTB}_{4}$.

Experiments were performed using four times the number of neutrophils to increase the sensitivity of the assay system for $\mathrm{OZ}$ stimulated $\mathrm{LTB}_{4}$ production. The $\mathrm{LTB}_{4}$ and metabolite peaks eluting from the HPLC were collected and further analyzed by ultraviolet spectroscopy (model HP 89500; Hewlett-Packard Corp., Palo Alto, CA) and found to have peak absorption at $270 \mathrm{~nm}$ with shoulders at 260 and $280 \mathrm{~nm}$ as previously described (20). In addition, a portion of the collected peak eluting as $\mathbf{L T B}_{4}$ was further characterized and quantitated as $\mathbf{L T B}_{4}$ by radioimmunoassay ( LTB $_{4}$ antisera; Advanced Magnetics, Cambridge, MA)

Spectrofluorimetric analysis of intracellular calcium. Neutrophils were loaded with Fura 2 by addition of $1 \mu \mathrm{M}$ Fura 2/AM to the cell suspension $\left(1 \times 10^{7}\right.$ cells $\left./ \mathrm{ml}\right)$ for $1 \mathrm{~h}$ at $37^{\circ} \mathrm{C}$ in a shaking water bath (23). After incubation the cells were centrifuged at $200 \mathrm{~g}$ for $10 \mathrm{~min}$ to remove extracellular dye and resuspended in HBSS (-). After loading the cell mixture was divided and portions analyzed fluorimetrically or incubated for $60 \mathrm{~min}$ without LPS or with LPS $10 \mathrm{ng} / \mathrm{ml}$. Following this incubation the mixture was again centrifuged at $200 \mathrm{~g}$ for $10 \mathrm{~min}$ and the supernatant decanted to remove any Fura 2 that may have leaked from the cells during the priming process. The cell mixture was then analyzed for baseline calcium concentration and followed by the addition of calcium and magnesium salts necessary to achieve a final solution equivalent to HBSS (+). After equilibration calcium concentrations are again determined followed by $\mathrm{OZ}$ stimulation.

Analysis was carried out using a luminescence spectrometer (LS-5B; Perkin-Elmer Corp., Norwalk, CT) in a wavelength scanning mode programmed with excitation wavelengths of 340 and $380 \mathrm{~nm}$ and an emission wavelength of $510 \mathrm{~nm}$. Repetitive scans were performed every $30 \mathrm{~s}$ following the addition of $\mathrm{OZ}$ for $4 \mathrm{~min}$ and again at 15,30 , and $45 \mathrm{~min}$ in some experiments. Cells were maintained at 
$37^{\circ} \mathrm{C}$ by a circulating water bath and continually stirred by a small magnetic stirring bar. Autofluorescence was determined for equivalent numbers of neutrophils not loaded with Fura 2 in the presence and absence of $\mathrm{OZ}$ and subtracted from individual measurements of fluorescence to assure that the signal represented only intracellular Fura 2 (23).

Calcium concentrations were determined using the following equation; $\left(\mathrm{Ca}^{2+}\right)=K_{\mathrm{d}} *\left(\left(R-R_{\min }\right) /\left(R_{\max }-R\right)\right) * B(23)$ with $R_{\min }$ and $R_{\max }$ determined for each individual experiment as suggested by Scanlon et al to account for incomplete deesterification of Fura 2/AM (23). $K_{\mathrm{d}}=224 \mathrm{nM}$ at $37^{\circ} \mathrm{C}, R=340 / 380$ ratio, and $B$ is the ratio of Fura 2 fluorescence at $380 \mathrm{~nm}$ in 0 and saturating calcium.

Statistical analysis. Parametric comparisons of the data generated at each concentration of LPS were done for each type and concentration of stimulant used. Data from experiments producing curves with many values was first converted to a single value based on the area under the curve. Data from experiments with a single end point were used in that form. Comparisons were than made using one-sided $t$ tests and Bonferroni's inequality to adjust for multiple comparisons (24). All reported experiments were done with $n=5$ except the calcium determinations where three separate experiments were each done in triplicate.

\section{Results}

$\mathrm{LTB}_{4}$ production by LPS-primed neutrophils stimulated with ionophore A23187. The most potent of the available stimuli for the generation of $\mathrm{LTB}_{4}$ by the neutrophil are the calcium ionophores $(25,26)$. In the presence of ionophore at a concentration of $0.05 \mu \mathrm{g} / \mathrm{ml}$, neutrophils incubated in the absence of LPS produced $8.2 \pm 2.4 \mathrm{ng}$ of $\mathrm{LTB}_{4}$ per million cells over 60 min. In contrast the cells incubated with LPS produced greater amounts of $\mathrm{LTB}_{4}$ in a concentration-dependent manner with the maximal generation being more than three times baseline production $\left(26.6 \pm 2.4 \mathrm{ng} / 10^{6}\right.$ cells $)$ at an LPS concentration of $10 \mathrm{ng} / \mathrm{ml}$ (Fig. 1). The time at which the presence of either $\mathrm{LTB}_{4}$ or the metabolites could be demonstrated was earlier in the LPS-treated cells, and the rate of production was also increased. There was no apparent difference in the duration of production of $\mathrm{LTB}_{4}$ in any of the groups. The concentration of

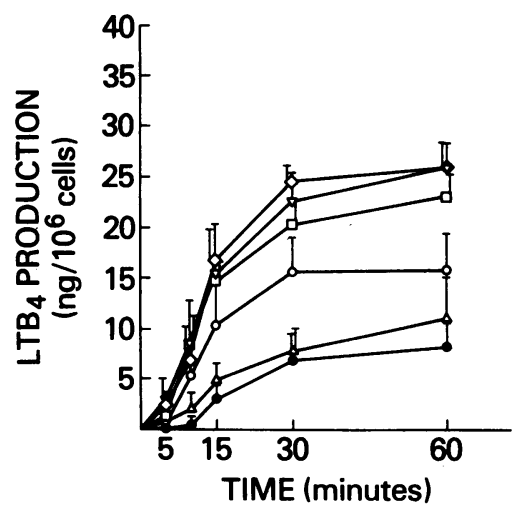

Figure 1. Effect of LPS on ionophore A23187 $(0.05 \mu \mathrm{g} / \mathrm{ml})$ induced production of $\mathrm{LTB}_{4}$ and metabolites by neutrophils. Neutrophils were incubated in HBSS $(-)$ alone $(\bullet)$ or with LPS for $60 \mathrm{~min}$ at $37^{\circ} \mathrm{C}$. LPS, $0.01 \mathrm{ng} / \mathrm{ml}(\Delta) ; 0.1$ $\mathrm{ng} / \mathrm{ml}(0) ; 1.0 \mathrm{ng} / \mathrm{ml}$ (); $10 \mathrm{ng} / \mathrm{ml}(\nabla)$; and $100 \mathrm{ng} / \mathrm{ml}(\diamond) . \mathrm{CaCl}_{2}$, $\mathrm{MgCl}_{2}$, and $\mathrm{MgSO}_{4}$ salts were added in appropriate amounts to have a final solution equivalent to HBSS $(+)$ and then stimulated with ionophore and incubated at $37^{\circ} \mathrm{C}$. Incubations were terminated at predetermined time points by addition of 1.5 vol iced ethanol followed by addition of $200 \mathrm{ng} \mathrm{PGB}_{2}$ as an internal standard. The cells were pelleted by centrifugation and the supernatant was extracted on ODS C18 cartridges for analysis by RPHPLC. Values are expressed as the total of $\mathrm{LTB}_{4}$ and metabolites present in the supernatant and are means of five separate experiments \pm SEM. $P<0.02$ for LPS concentrations $\geq 0.1 \mathrm{ng} / \mathrm{ml}$.
LPS at which a significant enhancement of $\mathrm{LTB}_{4}$ release could be demonstrated was $0.1 \mathrm{ng} / \mathrm{ml}$. In the absence of the second stimulus there was no $\mathrm{LTB}_{4}$ or metabolites detected in any experiment.

In addition to finding a difference in the amounts and rates of release of $\mathrm{LTB}_{4}$ and metabolites there was a marked difference in the ratio of $\mathrm{LTB}_{4}$ to metabolites between LPS-primed and unprimed neutrophils. The $\mathrm{LTB}_{4}$ produced by cells incubated in the absence of LPS was almost entirely comprised of metabolites with a maximum of $15 \%$ being $\mathrm{LTB}_{4}$ even at the earliest time points. In contrast, cells incubated in the presence of LPS $(10 \mathrm{ng} / \mathrm{ml})$ released up to $50 \%$ of the total as $\mathrm{LTB}_{4}$ before metabolism (Fig. 2).

Human neutrophils maximally produce $\mathrm{LTB}_{4}$ in response to ionophore at a concentration of $1.0 \mu \mathrm{g} / \mathrm{ml}$ (26). At this concentration of ionophore, LPS-induced priming of neutrophils could not be demonstrated.

The effect of duration of incubation on LPS-induced neutrophil priming. The effect of incubation duration on priming was studied. The incubation period associated with maximal priming of the neutrophil by LPS was $60 \mathrm{~min}$. No effect was seen at $0 \mathrm{~min} ; 68 \pm 6 \%$ of maximum was seen at $30 \mathrm{~min}$; and $38 \pm 8 \%$ of maximal at $90 \mathrm{~min}$. This decrease at $90 \mathrm{~min}$ was significantly decreased from maximum $(P \leq 0.02)$.

$L P S$-induced priming for enhanced release of $L T B_{4}$ by $O Z$, $P M A$, or FMLP-stimulated neutrophils. OZ-stimulated neutrophils produce $\mathrm{LTB}_{4}$ but in much smaller quantities than that produced with stimulation by the calcium ionophores $(25$, 26). Neutrophils incubated in the absence of LPS and then stimulated with $\mathrm{OZ}$ produced barely detectable amounts of $\mathrm{LTB}_{4}, 0.2 \pm 0.2 \mathrm{ng} / 10^{6}$ cells, with all of the $\mathrm{LTB}_{4}$ present as the hydroxyl and carboxyl metabolites. Cells incubated in the presence of LPS and then stimulated with $\mathrm{OZ}$ produced significantly greater amounts of $\mathrm{LTB}_{4}$. Priming with $10 \mathrm{ng} / \mathrm{ml} \mathrm{LPS}$

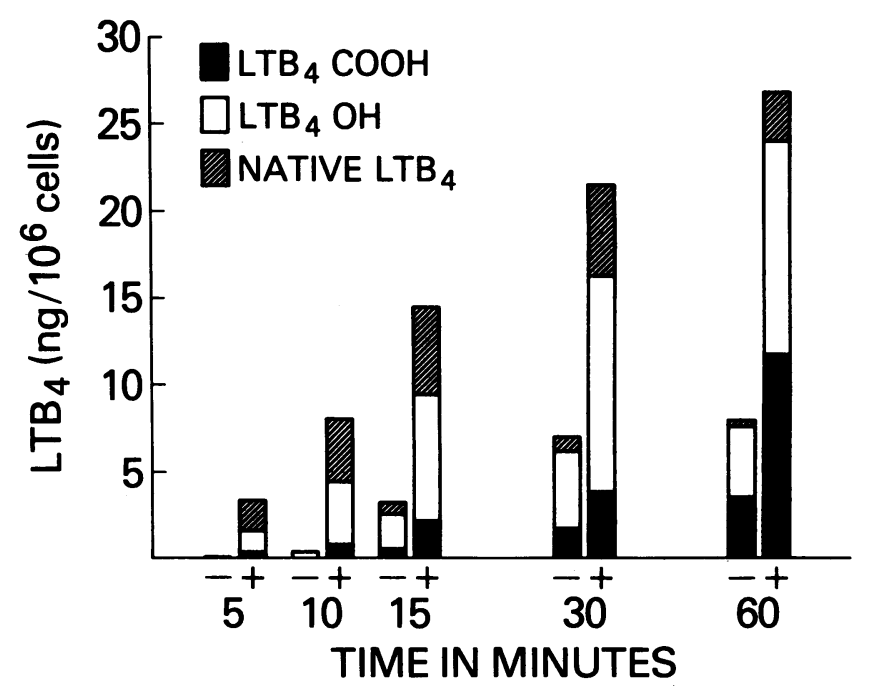

Figure 2. Comparison of the release of $\mathrm{LTB}_{4}$ vs metabolites by neutrophils incubated in HBSS (-) alone or LPS $(10 \mathrm{ng} / \mathrm{ml})$. Neutrophils were incubated for $60 \mathrm{~min}$ at $37^{\circ} \mathrm{C}$ and then stimulated with ionophore A23187 $(0.05 \mu \mathrm{g} / \mathrm{ml})$. Incubations were terminated at predetermined time points by addition of $1.5 \mathrm{vol}$ iced ethanol. Values represent the means of five separate experiments. The results of experiments done in the absence of LPS are noted with $(-)$ and experiments done in the presence of LPS $(10 \mathrm{ng} / \mathrm{ml})$ are represented with $(+)$. 
resulted in production of $2.8 \pm 0.8 \mathrm{ng} / 10^{6}$ cells (Fig. 3 ). The LPS-primed neutrophils produced native as well as metabolized $\mathrm{LTB}_{4}$ (Fig. 4). The lowest concentration of LPS necessary to result in enhanced production of $\mathrm{LTB}_{4}$ under these conditions was $0.1 \mathrm{ng} / \mathrm{ml}$. Intracellular retention of native $\mathrm{LTB}_{4}$ was not found in experiments designed to differentiate cell associated from secreted $\mathrm{LTB}_{4}$. This is in contrast to what has been previously described for neutrophils stimulated with unopsonized zymosan (17) and does not appear to be the reason for the absence of native $\mathrm{LTB}_{4}$ from the unprimed neutrophils.

FMLP does not cause $\mathrm{LTB}_{4}$ production by neutrophils in the absence of exogenous arachidonate $(25,26)$. Priming with LPS in concentrations ranging from 0.01 to $100 \mathrm{ng} / \mathrm{ml}$, did not result in the production of detectable amounts of $\mathrm{LTB}_{4}$ or metabolites by neutrophils incubated with FMLP $10^{-6} \mathrm{M}$ for up to $60 \mathrm{~min}$.

PMA, which is reported to act via enhanced activity of protein kinase $C(27,28)$, has been reported to prime neutrophils for enhanced production of $\operatorname{LTB}_{4}(29,30)$. Stimulation with PMA $(1 \mu \mathrm{g} / \mathrm{ml})$ alone for up to 5-10 min however was not sufficient for $\mathrm{LTB}_{4}$ production in these and other experiments $(25,29,30)$. We found that incubating neutrophils with PMA $(1 \mu \mathrm{g} / \mathrm{ml})$ for as long as $60 \mathrm{~min}$ did not result in production of $\mathrm{LTB}_{4}$ or metabolites. Significant amounts of $\mathrm{LTB}_{4}$ metabolites were however, detectable from neutrophils preincubated with LPS and then stimulated with PMA (Table I). The duration of incubation with PMA in these experiments was $60 \mathrm{~min}$. All of

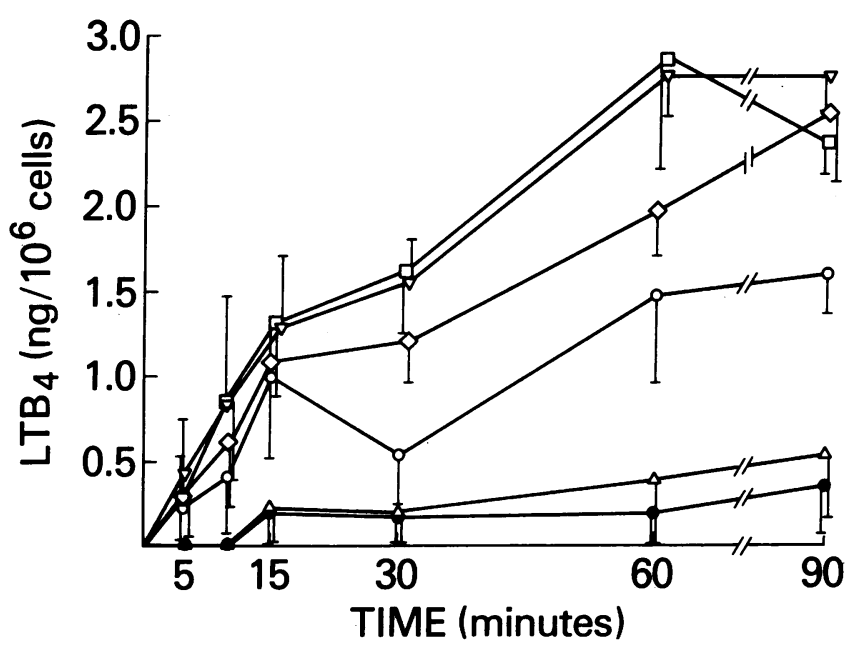

Figure 3. Effect of LPS on $\mathrm{OZ}(10 \mathrm{mg} / \mathrm{ml})$ induced production of $\mathrm{LTB}_{4}$ and metabolites by neutrophils. Neutrophils were incubated in HBSS (-) alone (๑) or with LPS for $60 \mathrm{~min}$ at $37^{\circ} \mathrm{C}$. LPS, 0.01 $\mathrm{ng} / \mathrm{ml}(\Delta) ; 0.1 \mathrm{ng} / \mathrm{ml}(0) ; 1.0 \mathrm{ng} / \mathrm{ml}(\square) ; 10 \mathrm{ng} / \mathrm{ml}(\nabla) ;$ and $100 \mathrm{ng} / \mathrm{ml}$ $(\diamond) . \mathrm{CaCl}_{2}, \mathrm{MgCl}_{2}$, and $\mathrm{MgSO}_{4}$ salts were added in appropriate amounts to have a final solution equivalent to HBSS (+) and then stimulated with ionophore and incubated at $37^{\circ} \mathrm{C}$. Incubations were terminated at predetermined time points by addition of $1.5 \mathrm{vol}$ iced ethanol followed by addition of $200 \mathrm{ng} \mathrm{PGB}_{2}$ as an internal standard. The cells were pelleted by centrifugation and the supernatant was extracted on ODS C18 cartridges for analysis by RP-HPLC. The peaks eluting as $\mathrm{LTB}_{4}$ and metabolites were verified quantitatively for $\mathrm{LTB}_{4}$ by RIA and qualitatively as $\mathrm{LTB}_{4}$ and metabolites by ultraviolet spectroscopy in the control and $10-\mathrm{ng} / \mathrm{ml}$ groups. Values are expressed as the total of $\mathrm{LTB}_{4}$ and metabolites present in the supernatant and are means of five separate experiments \pm SEM except for the 90-min point, which represents four experiments. $P<0.02$ for LPS concentrations $\geq 0.1 \mathrm{ng} / \mathrm{ml}$.

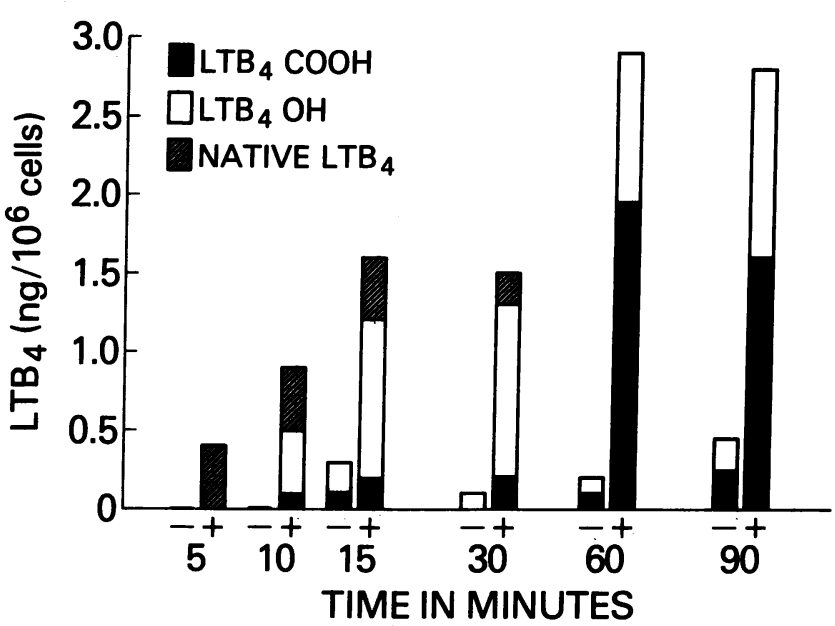

Figure 4. Comparison of the release of $\mathrm{LTB}_{4}$ vs. metabolites by neutrophils incubated in HBSS $(-)$ alone or LPS $(10 \mathrm{ng} / \mathrm{ml})$. Neutrophils were incubated for $60 \mathrm{~min}$ at $37^{\circ} \mathrm{C}$ and then stimulated with $\mathrm{OZ}(10 \mathrm{mg} / \mathrm{ml})$. Incubations were terminated at predetermined time points by addition of $1.5 \mathrm{vol}$ iced ethanol. Values represent the means of five separate experiments except the 90 -min values which represent the means of four separate experiments. The results of experiments done in the absence of LPS are noted with $(-)$ and experiments done in the presence of LPS $(10 \mathrm{ng} / \mathrm{ml})$ are represented with $(+)$.

the $\mathrm{LTB}_{4}$ detected was present as the metabolites. The lowest concentration of LPS necessary to consistently produce this effect is $0.1 \mathrm{ng} / \mathrm{ml}$.

$O Z$ effects on intracellular calcium in primed and unprimed neutrophils. Calculated intracellular calcium concentrations immediately after the incubation period with Fura 2/AM were essentially zero. Following the addition of calcium to the mixture the concentration rose to $40 \mathrm{nM}$ in both control and LPS-treated cells. Upon addition of zymosan to the mixture there was a rise in the calcium levels plateauing at 90-120 $\mathrm{s}$ (Fig. 5). This is consistent with previously reported data (31). There was no significant difference in baseline calcium or cal-

Table I. Effect of LPS on PMA (I $\mu \mathrm{g} / \mathrm{ml})$ Induced Production of $\mathrm{LTB}_{4}$ and Metabolites by Neutrophils

\begin{tabular}{cc}
\hline LPS & LTB $_{4}$ \\
\hline$n g / m l$ & $n g / 10^{6} P M N$ \\
0.00 & $0.18 \pm 0.08$ \\
0.01 & $0.21 \pm 0.07$ \\
0.10 & $1.24 \pm 0.14$ \\
1.00 & $2.56 \pm 0.33$ \\
10.0 & $2.74 \pm 0.23$ \\
100 & $2.94 \pm 0.24$
\end{tabular}

Neutrophils were incubated in HBSS (-) alone or LPS for $60 \mathrm{~min}$ at $37^{\circ} \mathrm{C} . \mathrm{CaCl}_{2}, \mathrm{MgCl}_{2}$, and $\mathrm{MgSO}_{4}$ salts were added in appropriate amounts to have a final solution equivalent to HBSS $(+)$ and then stimulated with PMA and incubated at $37^{\circ} \mathrm{C}$. Incubations were terminated at $60 \mathrm{~min}$ by addition of $1.5 \mathrm{vol}$ iced ethanol followed by addition of $200 \mathrm{ng} \mathrm{PGB}_{2}$. Values are expressed as the total of $\mathrm{LTB}_{4}$ and metabolites present in the supernatant and are means of five separate experiments \pm SEM. $P<0.02$ for $L P S \geq 0.1 \mathrm{ng} / \mathrm{ml} \mathrm{com-}$ pared to control, $P<0.05$ for LPS $\geq 1.0 \mathrm{ng} / \mathrm{ml}$ compared to LPS $=0.1 \mathrm{ng} / \mathrm{ml}$. 


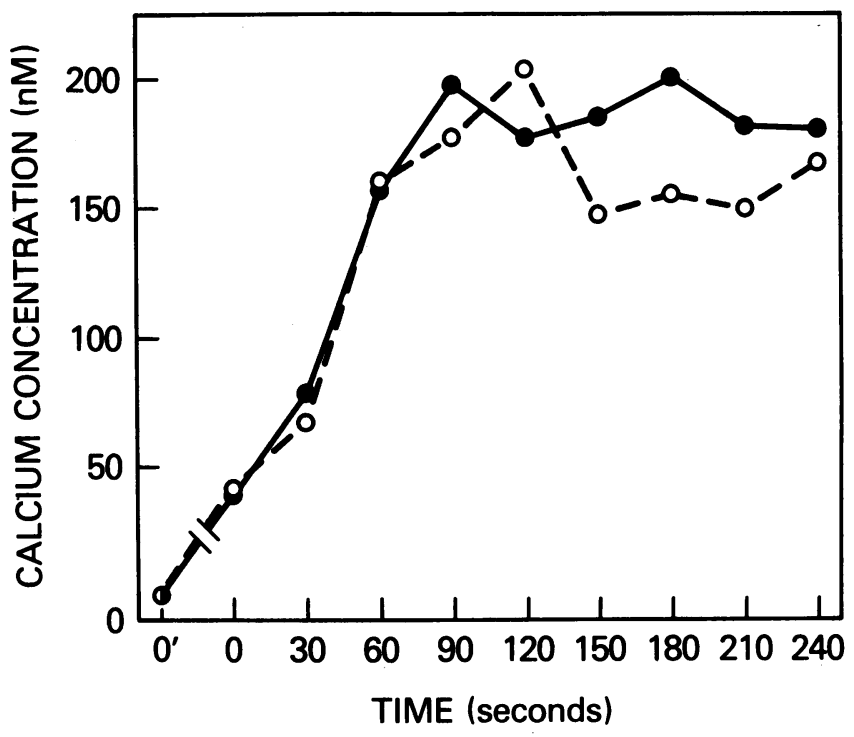

Figure 5. Effect of LPS on changes in calcium concentration in neutrophils upon stimulation with opsonized zymosan. Neutrophils were incubated in HBSS (-) alone (๑) or LPS $10 \mathrm{ng} / \mathrm{ml} \mathrm{(0)} \mathrm{for} 60 \mathrm{~min}$ at $37^{\circ} \mathrm{C} . \mathrm{CaCl}_{2}, \mathrm{MgCl}_{2}$, and $\mathrm{MgSO}_{4}$ salts were added in appropriate amounts to have a final solution equivalent to HBSS $(+)$ and then stimulated with $\mathrm{OZ} 10 \mathrm{mg} / \mathrm{ml}$. Calcium concentration was calculated from the ratio of fluorescent intensities measured at 340- and 380$\mathrm{nM}$ excitation, 510-nM emission, using the standard procedure described under Methods. $T=0^{\prime}$ represents measurements made before addition of calcium and magnesium salts to the cell suspension. $\mathrm{T}=$ 0 represents measurements made prior to the addition of $\mathrm{OZ}$. The calcium concentration increased rapidly plateauing at $90-120 \mathrm{~s}$ and then slowly drifted downward but remained elevated with levels at $45 \mathrm{~min}$ of 85 and $90 \mathrm{nM}$ for control and primed cells, respectively.

cium flux between cells primed with LPS and unprimed cells. Frequent measurements were made for only the first $5 \mathrm{~min}$, however periodic measurements made over the next $45 \mathrm{~min}$ showed the calcium level slowly drifting downward but to have remained elevated with levels at $45 \mathrm{~min}$ of 85 and $90 \mathrm{nM}$ for control and primed cells, respectively.

\section{Discussion}

The results of these studies show that human neutrophils can be primed for enhanced production and release of $\mathrm{LTB}_{4}$ by exposure to picogram quantities of LPS. The time of incubation with LPS necessary for maximum enhancement of $\mathrm{LTB}_{4}$ production is $60 \mathrm{~min}$. There is a significant effect seen at 30 min and a decreasing effect with prolonged incubation. An identical time course was found in studies of priming for superoxide generation (data not shown). The most potent stimuli for the production of $\mathrm{LTB}_{4}$ by neutrophils are the calcium ionophores $(25,26)$. Incubation of human neutrophils with the ionophore at a concentration of $1.0 \mu \mathrm{g} / \mathrm{ml}$ results in maximal production of $\mathrm{LTB}_{4}$. Enhancement of $\mathrm{LTB}_{4}$ production by LPS is not seen when the cells are maximally stimulated. Using a much lower concentration of ionophore $(0.05 \mu \mathrm{g} / \mathrm{ml})$, as little as $0.1 \mathrm{ng} / \mathrm{ml}$ of LPS is necessary to significantly enhance the production of $\mathrm{LTB}_{4}$ by neutrophils. LPS alone does not result in the release of detectable amounts of $\mathrm{LTB}_{4}$ by the neutrophils.

The effect of LPS on the generation of $\mathrm{LTB}_{4}$ by ionophore-stimulated neutrophils is similar to increasing the con- centration of ionophore. Prior incubation with LPS does not increase $\mathrm{LTB}_{4}$ production to a higher maximum. This suggests that the mechanism by which LPS is affecting $\mathrm{LTB}_{4}$ production might occur by modulation of cytosolic free calcium concentrations or by altering the activity of a calcium sensitive enzyme system.

$\mathrm{OZ}$ stimulation of neutrophils has been shown to result in the production of very small amounts of $\operatorname{LTB}_{4}(25,26)$. The effect of $\mathrm{OZ}$ stimulation of neutrophils has been shown to be, at least in part, due to an increase in cytosolic free calcium (31). In the macrophage there also appears to be a calcium-dependent zymosan effect on phospholipase $\mathrm{C}$, which may play a role in arachidonic acid release $(32,33)$. Our studies confirm that $\mathrm{OZ}$ stimulation of neutrophils results in an increase in intracellular calcium. We have also found that $\mathrm{OZ}$ stimulation of neutrophils in the absence of extracellular calcium does not result in $\mathrm{LTB}_{4}$ production (data not shown). We did not find any significant effect of priming with LPS on this alteration in calcium levels. Coupled with the ionophore data this would seem to implicate a calcium dependent enzyme system as the likely site of action for LPS priming. There are multiple potential sights for this type of effect in the neutrophil including the phospholipases $A_{2}$ and $C(34)$, protein kinase $C(35)$, phosphoinositol metabolism $(36,37)$, and 5-lipoxygenase (38). All of these systems have been implicated as being responsible for the differences in $\mathrm{LTB}_{4}$ production resulting from different stimuli.

The chemo-attractant tripeptide FMLP is reported to result in production of $\mathrm{LTB}_{4}$ by neutrophils only in the presence of a marked excess of arachidonate $(25,26)$. Arachidonic acid at these concentrations has been postulated to be effecting either phospholipase $C(26)$ or 5-lipoxygenase (25) activity directly, in addition to acting as substrate. FMLP acts at least in part by producing an increase in cytosolic free calcium which is brief and not sustained $(39,40)$ and also appears to have an effect on arachidonate mobilization and redistribution (41, 42). It does not however result in metabolism of the arachidonic acid to $\mathrm{LTB}_{4}$. LPS does not potentiate production of $\mathrm{LTB}_{4}$ by neutrophils when FMLP is the second stimulant. The action of LPS in this system is therefore distinctly different than that of exogenous arachidonic acid. 5-Lipoxygenase stimulation as the sole site of action for LPS would be unlikely and certainly would not explain previously described alterations in oxygen metabolism (1). These observations however do not rule out an LPS effect on 5-lipoxygenase and it is likely that a number of different sites could be affected.

It has been suggested that LPS enhances protein kinase C activity in neutrophils (43) and it seems reasonable to consider this a likely mechanism for the priming effect. PMA, a protein kinase $C$ activator (44), has not been found to stimulate neutrophil production of $\mathrm{LTB}_{4}$, but has been shown to potentiate the production by ionophore stimulated neutrophils $(29,30)$. Cells that are incubated with LPS and then with PMA produce LTB $_{4}$ in significant amounts. The time course of PMA induced priming appears to differ from that of LPS priming of neutrophils. LPS requires a significant period of preincubation whereas PMA is effective when added simultaneously with ionophore. PMA also differs from LPS in its effect on $\mathrm{LTB}_{4}$ generation by OZ-stimulated neutrophils. LPS can prime for enhanced generation of $\mathrm{LTB}_{4}$ with OZ; PMA has been shown to have no effect (25). The conditions under which PMA enhancement of $\mathrm{LTB}_{4}$ production by ionophore-stimulated neu- 
trophils occurs do have similarities with those necessary for priming by LPS. The PMA enhancement of $\mathrm{LTB}_{4}$ production by ionophore-stimulated neutrophils occurs with an ionophore concentration at which the effect of LPS can also be shown $(29,30)$. PMA has been shown to actually decrease intracellular calcium or to not affect it at all $(45,46)$. Our data shows no effect of LPS on cytosolic calcium concentrations. If the priming affect of LPS is via modulation of protein kinase $C$ activity it is likely to be by a different mechanism than the PMA effect, since neither of these stimulants alone results in production of $\mathrm{LTB}_{4}$, but together they do. It seems most likely that their actions are similar but at separate sites, both of which must be stimulated to result in production of $\mathrm{LTB}_{4}$ by the neutrophil. In macrophages LPS has been shown to cause the myristoylation of distinct membrane proteins with a temporal sequence similar to that required for priming of neutrophils (47). One of these myristoylated proteins, with a relative molecular mass of $68 \mathrm{kD}$, has been shown to be a protein kinase $C$ substrate and to undergo membrane association and increased phosphorylation following LPS priming (48). This is one possible explanation for the LPS effect that is consistent with our data. It is also possible that the LPS enhancement of $\mathrm{LTB}_{4}$ production is not via protein kinase $C$, but is a similar type of effect on another or several of the calcium-regulated enzyme systems involved in arachidonic acid liberalization and LTB $_{4}$ production. In the macrophage, LPS not only enhances release of eicosanoids but decreases the lag phase between stimulation and eicosanoid release. Enhanced phospholipase activity has been postulated as a mechanism for this (3). Our observations in human neutrophils that not only $\mathrm{LTB}_{4}$ production is increased, but that the rate of this production is also increased with LPS priming are consistent with this hypothesis. Enhanced substrate availability or mobilization would certainly explain these findings.

In addition to having an effect on $\mathrm{LTB}_{4}$ production by neutrophils our data suggests that LPS priming may have an effect on $\mathrm{LTB}_{4}$ metabolism as well. Experiments with zymosan and ionophore A23187 $(0.05 \mu \mathrm{g} / \mathrm{ml})$ showed a marked difference in the percent of $\mathrm{LTB}_{4}$ present as metabolites between primed and unprimed neutrophils. Native $\mathrm{LTB}_{4}$ was present only in primed neutrophils, not controls when $\mathrm{OZ}$ was used as the stimulant. Native $\mathrm{LTB}_{4}$ was present as a greater percentage of total in LPS primed cells in the experiments with ionophore as the stimulant. This effect does not appear to be simply mass action as it is true when as little as $10 \mathrm{pg} / \mathrm{ml}$ LPS was used to prime the cells when there was no difference in actual production (data not shown). We also found no difference in intracellular retention of native $\mathrm{LTB}_{4}$ when separate extraction techniques were used for the supernatant and the cell pellet in contrast to what has been shown when unopsonized zymosan is used as a stimulant (17). It would appear that LPS is in some way impairing the cells' mechanism for metabolizing $\mathrm{LTB}_{4}$ resulting in an apparent decrease rate of oxidation of native $\mathrm{LTB}_{4}$. Persistence of native $\mathrm{LTB}_{4}$ in the microenvironment may have a role in further amplification of the effects of increased production resulting from LPS priming.

$\mathrm{LTB}_{4}$ has been postulated to have a significant role in modulating host defense mechanisms $(6-11,49)$. The LPS-priming of human neutrophils for enhanced $\mathrm{LTB}_{4}$ production might play a role in immune response modulation during gram negative septicemia. This priming affect can be shown with as little as $0.1 \mathrm{ng} / \mathrm{ml}$ of LPS, an amount consistent with those measured in humans with septic shock. This is less than previously shown for priming for enhanced superoxide generation $(1,15)$, or for priming of macrophages for enhanced eicosanoid release (3).

$\mathrm{LTB}_{4}$ has also been implicated in several types of pulmonary parenchymal injury (50-52). Serious infections with gram negative bacteria are frequently complicated by the adult respiratory distress syndrome (ARDS), an illness characterized by a significant increase in pulmonary vascular permeability. This event is felt to be, at least in part, mediated by neutrophils (53). If LPS primed neutrophils for enhanced $\mathrm{LTB}_{4}$ production in vivo, subsequent stimulation by activated complement proteins or by phagocytosis of pathogens might result in increased production and release of $\mathrm{LTB}_{4}$ into multiple tissues such as lung, kidney, liver and brain. The action of $\mathrm{LTB}_{4}$ as a cause of neutrophil dependent increases in vascular permeability $(12,13)$ might play a significant role in the development of ARDS as well as multiple system organ failure. This latter syndrome has been recognized as one of the major causes of patient demise during human septic shock (54).

\section{Acknowledgments}

The authors would like to extend their thanks to Dr. Steven Shak, Assistant Professor of Medicine and Pharmacology, New York University School of Medicine for his invaluable assistance in designing the methodology used in these studies. We would also like to thank Dr. Robert Wesley for his guidance in the statistical analysis.

\section{References}

1. Guthrie, L. A., L. C. McPhail, P. M. Henson, and J. R. Johnston. 1984. Priming of neutrophils for enhanced release of oxygen metabolites by bacterial lipopolysaccharide. J. Exp. Med. 160:1656-1671.

2. Levin, J., T. E. Poore, N. P. Zauber, and R. S. Oser. 1970. Detection of endotoxin in the blood of patients with sepsis due to gram-negative bacteria. N. Engl. J. Med. 283:1313-1316.

3. Aderem, A. A., D. S. Cohen, S. D. Wright, and Z. A. Cohn. 1986. Bacterial lipopolysaccharides prime macrophages for enhanced release of arachidonic acid metabolites. J. Exp. Med. 164:165-179.

4. Walsh, C. E., B. M. Waite, M. J. Thomas, and L. R. DeChalet. 1981. Release and metabolism of arachidonic acid in human neutrophils. J. Biol. Chem. 256:7228-7234.

5. Lewis, R. A., and K. F. Austen. 1984. The biologically active leukotrienes. Biosynthesis, metabolism, receptors, functions, and pharmacology. J. Clin. Invest. 73:889-897.

6. Ford-Hutchinson, A. W., M. A. Bray, M. V. Doig, M. E. Shipley, and M. J. H. Smith. 1980. Leukotriene $B_{4}$, a potent chemokinetic and aggregating substance released from polymorphonuclear leukocytes. Nature (Lond.). 286:264-265.

7. Goetzl, E. H., and W. C. Pickett. 1980. The human PMN leukocyte chemotactic activity of complex hydroxy-eicosatetraenoic acids (HETEs). J. Immunol. 125:1789-1791.

8. Feinmark, S. J., J. A. Lindgren, H. E. Claesson, C. Malmsten, and B. Samuelsson. 1981. Stimulation of human leukocyte degranulation by leukotriene B4 and its omega-oxidized metabolites. FEBS (Fed. Eur. Biochem. Soc.) Lett. 136:141-144.

9. Hartiala, K. T., I. G. Scott, M. K. Viljanen, and E. O. Akerman. 1987. Lack of correlation between calcium mobilization and respiratory burst activation induced by chemotactic factors in rabbit polymorphonuclear leukocytes. Biochem. Biophys. Res. Commun. 144:794-800. 
10. Leung, K. H., M. J. Ehrke, and E. Mihich. 1982. Modulation of the development of cell-mediated immunity: possible role of the products of cyclo-oxygenase and the lipoxygenase products of arachidonic acid metabolism. Int. J. Immunopharmacol. 4:195-204.

11. Rola-Plesczynski, M., P. Borgeat, and P. Sirois. 1982. Leukotriene B4 induces human suppressor lymphocytes. Biochem. Biophys. Res. Commun. 108:1531-1537.

12. Wedmore, C. V., and T. J. Williams. 1981. Control of vascular permeability by polymorphonuclear leukocytes in inflammation. $\mathrm{Na}$ ture (Lond.). 289:646-650.

13. Bjork, J., P. Hedvquist, and K. E. Arfors. 1982. Increase in vascular permeability induced by leukotriene $B_{4}$ and the role of polymorphonuclear leukocytes. Inflammation. 6:189-200.

14. Atkins, E., and C. Heijn, Jr. 1965. Studies on tuberculin fever III: mechanisms involved in the release of endogenous pyrogen in vitro. J. Exp. Med. 122:207-235.

15. Danner, R. L., K. A. Joiner, and J. E. Parrillo. 1987. Inhibition of Endotoxin-induced priming of human neutrophils by lipid $X$ and 3-AZA-lipid X. J. Clin. Invest. 80:605-612.

16. Marom, Z., J. H. Shelhamer, and M. Kaliner. 1984. Human pulmonary macrophage-derived mucus secretagogue. J. Exp. Med. 159:844-860.

17. Williams, J. D., T. H. Lee, R. A. Lewis, and F. Austen. 1985. Intracellular retention of the 5-lipoxygenase pathway product, leukotriene B4, by human neutrophils activated with unopsonized zymosan. J. Immunol. 134:2624-2630.

18. Shak, S. 1987. Leukotriene B4 catabolism: quantitation of leukotriene B4 and its omega-oxidation products by reversed-phase highperformance liquid chromatography. Methods Enzymol. 141:355371.

19. Borgeat, P., and B. Samuelsson. 1979. Transformation of arachidonic acid by rabbit polymorphonuclear leukocytes. J. Biol. Chem. 254:2643-2646.

20. Borgeat, P., S. Picard, and P. Vallerand. 1981. Transformation of arachidonic acid in leukocytes. Isolation and structural analysis of a novel dihydroxy derivative. Prostaglandins Medicine. 6:557-570.

21. Green, K., M. Hamberg, B. Samuelsson, M. Smigel, and J. C. Frolich. 1978. Measurement of prostaglandins, thromboxanes, prostacyclin and their metabolites by gas-liquid chromatography-mass spectrometry. Adv. Prostaglandin Thromboxane Res. 5:39-94.

22. Shak, S., and I. M. Goldstein. 1984. Omega-oxidation is the major pathway for the catabolism of leukotriene B4 in human polymorphonuclear leukocytes. J. Biol. Chem. 259:10181-10187.

23. Scanlon, M., D. A. Williams, and F. S. Fay. 1987. A calciuminsensitive form of Fura-2 associated with polymorphonuclear leukocytes, assessment and accurate calcium measurements. J. Biol. Chem. 262:6308-6312.

24. Miller, R. 1986. Beyond Anova, Basics of Applied Statistics. John Wiley and Sons, New York. 74-75.

25. Haines, K. A., K. N. Giedd, A. M. Rich, H. M. Korchak, and G. Weissmann. 1987. The leukotriene B4 paradox: neutrophils can, but will not, respond to ligand-receptor interactions by forming leukotriene B4 or its omega-metabolites. J. Biochem. 241:55-62.

26. Palmer, R. M. J., and J. A. Salmon. 1983. Release of leukotriene B4 from human neutrophils and its relationship to degranulation induced by $\mathrm{N}$-formyl-methionyl-leucyl-phenylalanine, serum treated zymosan and the ionophore A23187. Immunology. 50:65-73.

27. Castagna, M., Y. Takai, K. Kaibuchi, K. Sano, U. Kikkawa, and Y. Nishizuka. 1982. Direct activation of calcium-activated, phospholipid-dependent protein kinase by tumor-promoting phorbol esters. J. Biol. Chem. 257:7847-7851.

28. Nishizuka, Y. 1986. Studies and perspectives of protein kinase C. Science (Wash. DC). 233:305-312.

29. Liles, W. C., K. E. Meier, and W. R. Henderson. 1987. Phorbol Myristate acetate and the calcium ionophore A23187 synergistically induce release of $\mathrm{LTB}_{4}$ by human neutrophils. Involvement of protein kinase $\mathrm{C}$ activation in regulation of the 5-lipoxygenase pathway. $J$. Immunol. 138:3396-3402.

30. McColl, S. R., N. P. Hurst, and L. G. Cleland. 1986. Modulation by phorbol myristate acetate of arachidonic acid release and leukotriene synthesis by human polymorphonuclear leukocytes stimulated with A23187. Biochem. Biophys. Res. Commun. 141:399-404.

31. Meshulam, T., R. D. Diamond, C. A. Lyman, D. R. Wysong, and D. A. Melnick. 1988. Temporal association of calcium mobilization, inositol triphosphate generation, and superoxide anion release by human neutrophils activated by serum opsonized and nonopsonized particulate stimuli. Biochem. Biophys. Res. Commun. 150:532-539.

32. Moscat, J., M. Aracil, E. Diez, J. Balsinde, P. G. Barreno, and A. M. Municio. 1986. Intracellular calcium requirements for zymosan-stimulated phosphoinositide hydrolysis in mouse peritoneal macrophages. Biochem. Biophys. Res. Commun. 134:367-371.

33. Emillson, A., and R. Sundler. 1984. Differential activation of phosphatidylinositol deacylation and a pathway via diphosphoinositide in macrophages responding to zymosan and ionophore A23187. J. Biol. Chem. 259:3111-3116.

34. Blackwell, G. J., and R. J. Flower. 1983. Inhibition of phospholipase. Br. Med. Bull. 39:260-264.

35. McPhail, L. C., C. C. Clayton, and R. Snyderman. 1984. A potential second messenger role for unsaturated fatty acids. Activation of calcium-dependent protein kinase. Science (Wash. DC). 224:622625.

36. Majerus, P. W., T. M. Connolly, H. Deckmyn, T. S. Ross, T. E. Bross, H. Ishii, V. S. Bansal, and D. B. Wilson. 1986. The metabolism of phosphoinositide-derived messenger molecules. Science (Wash. DC). 234:1519-1526.

37. Berridge, M. J., and R. F. Irvine. 1984. Inositol triphosphate, a novel second messenger in cellular signal transduction. Nature (Lond.). 312:315-321.

38. Taylor, G. W., and H. R. Morris. 1983. Lipoxygenase pathways. Br. Med. Bull. 39:219-222.

39. Korchak, H. M., L. E. Rutherford, and G. Weissman. 1984. Stimulus response coupling in the human neutrophil. Kinetic analysis of changes in calcium permeability. J. Biol. Chem. 259:4070-4075.

40. Korchak, H. M., K. Vienne, L. E. Rutherford, C. Wilkenfeld, M. C. Filkenstein, and G. Weissman. 1984. Stimulus response coupling in the human neutrophil. Temporal analysis of changes in cytosolic calcium and calcium efflux. J. Biol. Chem. 259:4076-4082.

41. Hirata, F., B. A. Corcoran, K. Venkatasubramanian, E. Schiffman, and J. Axelrod. 1979. Chemoattractants stimulate degradation of methylated phospholipids and release of arachidonic acid in rabbit leukocytes. Proc. Natl. Acad. Sci. USA. 76:2640-2643.

42. Wynkoop, E. M., M. J. Broekman, H. M. Korchak, A. J. Marcus, and G. Weissman. 1986. Phospholipid metabolism in human neutrophils activated by $N$-formyl-methionyl-leucyl-phenylalanine. Biochem. J. 236:829-837.

43. Wightman, P. D., and C. R. Raetz. 1984. The activation of protein kinase $\mathrm{C}$ by biologically active lipid moieties of lipopolysaccharide. J. Biol. Chem. 259:10048-10052.

44. Kraft, A. S., and W. B. Anderson. 1983. Phorbol esters increase the amount of calcium, phospholipid-dependent protein kinase associated with plasma membrane. Nature (Lond.). 301:621-623.

45. DiVirgilio, F., D. P. Lew, and T. Pozzan. 1984. Protein kinase $\mathrm{C}$ activation of physiological processes in human neutrophils at vanishingly small cytosolic calcium levels. Nature (Lond.). 310:691-693.

46. Sha'afi, R. I., J. R. White, T. F. P. Molski, J. Shefcyk, M. Volpi, P. H. Naccache, and M. B. Feinstein. 1983. Phorbol 12-myristate 13-acetate activates rabbit neutrophils without an apparent rise in the level of intracellular free calcium. Biochem. Biophys. Res. Commun. 114:638-693.

47. Aderem, A. A., M. W. Keum, E. Pure, and Z. A. Cohn. 1986. Bacterial lipopolysaccharides, phorbol myristate acetate, and zymosan induce the myristoylation of specific macrophage proteins. Proc. Natl. Acad. Sci. USA. 83:5817-5821. 
48. Aderem, A. A., K. A. Albert, M. M. Keum, J. K. T. Wang, P. Greengard, and Z. A. Cohn. 1988. Stimulus-dependent myristoylation of a major substrate for protein kinase C. Nature (Lond.). 332:362364.

49. Lewis, G. P. 1983. Immunoregulatory activity of metabolites of arachidonic acid and their role in inflammation. Br. Med. Bull. 39:243-248.

50. Taniguchi, H., F. Taki, K. Takagi, T. Satake, S. Sugiyama, and T. Ozawa. 1986. The role of leukotriene B4 in the genesis of oxygen toxicity in the lung. Am. Rev. Respir. Dis. 133:805-808.

51. Westcott, J. K., K. R. Stenmark, and R. C. Murphy. 1986.
Analysis of leukotriene B4 in human lung lavage by HPLC and mass spectrometry. Prostaglandins. 31:227-237.

52. Garcia, J. G. N., T. C. Noonan, W. Jubiz, and A. B. Malik. 1987. Leukotrienes and the pulmonary microcirculation. Am. Rev. Respir. Dis. 136:161-168.

53. Warshawski, F. J., W. J. Sibbald, A. A. Driedger, and H. Cheung. 1986. Abnormal neutrophil-pulmonary interaction in the adult respiratory distress syndrome. Am. Rev. Respir. Dis. 133:797804.

54. Parker, M. M., J. H. Shelhamer, C. Natanson, D. W. Alling, and J. E. Parrillo. 1987. Serial cardiovascular variables in survivors and nonsurvivors of human septic shock. Heart rate as an early predictor of prognosis. Crit. Care Med. 15:923-929. 